\title{
A paradigm shift in eye banking: how new models are challenging the status quo
}

This article was published in the following Dove Medical Press journal: Clinical Ophthalmology

\author{
Majid Moshirfar ${ }^{1-3}$ \\ Jackson L Goldberg ${ }^{4}$ \\ Tanner W Brown ${ }^{4}$ \\ William D Wagner ${ }^{5}$ \\ Yasmyne C Ronquillo' \\ 'HDR Research Center, Hoopes \\ Vision, Draper, UT, USA; ${ }^{2}$ Department \\ of Ophthalmology and Visual Sciences, \\ John A. Moran Eye Center, University \\ of Utah School of Medicine, Salt Lake \\ City, UT, USA; ${ }^{3}$ Utah Lions Eye Bank, \\ John Moran Eye Center, Murray, UT, \\ USA; ${ }^{4}$ The University of Texas Health \\ Science Center at Houston School of \\ Medicine, Houston, TX, USA; ${ }^{5}$ Virginia \\ Commonwealth University School of \\ Medicine, Richmond, VA, USA
}

Correspondence: Majid Moshirfar HDR Research Center, Hoopes Vision, I I 820 South State Street, Suite 200 Draper, UT 84020, USA

Tel + I 8015680200

Fax + I 80I 5630200

Email majid.moshirfar@hsc.utah.edu

\begin{abstract}
This article presents a fact-based, direct approach in order to evaluate the strengths and short comings of both local eye banks and larger companies that have penetrated the market of eye donation. By taking a non-biased approach to the topic, the goal of this article is to create a platform, which furthers the discussion. We focus on SightLife and CorneaGen as well as local eye banks and how their models differ in terms of tissue procurement, distribution, and surgeon partnership.
\end{abstract}

Keywords: SightLife, CorneaGen, Lions Eye Bank, cornea transplant

\section{Introduction}

As globalization makes headway into medicine, the importance of research and development, logistics, business, and entrepreneurship has followed shortly behind. While the world continues to improve in many ways, it is also a landscape where ethical boundaries are becoming more difficult to decipher. New technology and ideas raise questions and underscore the importance of striking a balance between scientific advancement, ethical values, and moral judgment. The shift of corneal tissue procurement, transport, and surgeon partnership from local, community-based eye banks to larger companies is an example of innovation that comes with dilemmas. This shift has generated a significant discussion among cornea surgeons. While local eye banks and the larger organizations they compete with have the same goal of eliminating corneal blindness, their methods are vastly different and each present unique challenges and opportunities. The goal of this article is to generate further dialog on the emergence of larger companies such as the non-profit SightLife (Seattle, WA, USA) and its daughter company, for-profit CorneaGen (Seattle, WA, USA) (formerly SightLife Surgical). We will take a non-biased approach when discussing what this means for the future of eye banking. We believe that if we are confronted with this dilemma, other cornea surgeons may have the same questions.

The first traditional eye bank was founded in 1944 to retrieve and store eyes for cornea transplantation and research. ${ }^{1}$ Since this time, the importance of corneal blindness cannot be overstated, as diseases affecting the cornea are currently the third leading cause of blindness worldwide. ${ }^{2}$ Corneal transplants have been instrumental in their ability to combat corneal pathology as a cause of blindness. For example, in $2012,184,576$ corneal transplants were performed in 116 countries for a large variety of indications. ${ }^{2}$ Because of this high demand and the success of traditional distribution methods to meet that demand, there is an amount of uncertainty among cornea surgeons about what effects changing the eye banking system might have.

SightLife, a non-profit company that partners with organ procurement organizations (OPOs) and hospital systems in the harvesting of tissue for both research and 
transplantation, was originally founded in 1969 and is quickly gaining a large foothold in the marketplace. ${ }^{3}$ It has been the largest eye bank in the US since $2009 .{ }^{3}$ To put their growth into perspective, in 2017, the combined SightLife consortium provided over 35,000 corneas for transplant worldwide with $\sim 15,000$ being transplanted in the US, roughly $30 \%$ of the total number of corneal transplants. ${ }^{4}$ In addition to that astounding Figure, SightLife added over 70 new cornea surgeon colleagues in 2017 and surgeon satisfaction with their products, services, and support approaches $100 \%$. If their growth rate continues at this pace for the next 5 years as they predict, they will supply tissue for $>50 \%$ of the corneal transplants worldwide.

According to the 2017 Eye Bank Association of America (EBAA) report, which is based on the final numbers of corneas recovered by US-based accredited eye banks, there was a fall from 136,318 in 2017 to 135,203 in 2016, down nearly a full percentage point. While national supply of corneas harvested decreased, there was a concurrent increase in demand for corneal transplants. For example, there were over $2 \%$ more corneas transplanted in the US in $2017(50,934)$ than in $2016(49,869) .{ }^{5,6}$ Opponents of SightLife's business model point out that if SightLife's numbers of corneas harvested and transplanted are increasing, but overall national numbers are not, SightLife's gain is likely coming at another eye bank's loss.

It is possible that the traditional eye bank system, which is rooted in local service and cooperation with local stakeholders, is a reason a surplus of tissue exists. Another key reason for this surplus is the revised uniformed anatomical gift act, which allows the use of life-sustaining technology in order to maximize organ procurement. ${ }^{7}$ A surplus of tissue is critical to have, as EBAA statistics show that in 2017 it took almost 1.5 recovered corneas to result in one transplantable cornea. ${ }^{5}$ Surgeons may receive tissue that does not meet their requirements for transplantation, and several other specimens may not pass stringent final donor eligibility testing due to medical findings or positive serologies, for example.

A further concern of those skeptical of Sightlife's model is that, while a surplus exists, it is feasible that an artificial shortage may be created at the community level. This is potentially problematic since a surgeon's community eye bank may have fewer specimens readily available in the scenario of a same-day, emergency surgery. However, in territories serviced by SightLife, there are agreements in place with local eye banks to combat this scenario. Furthermore, communities located in parts of the country with severe winter weather, are at risk by relying solely on air transportation from distant centers, leaving the patient to bear the consequence. SightLife has only the following five centers: Seattle, WA, Irvine, CA, San Francisco, CA, Winston-Salem, NC, and Bethlehem, PA. The scarcity of these centers may create supply chain issues. Regardless of how advanced society has become, the constraints of time, distance, and weather are still factors that must be considered. In contrast, most, if not all cornea surgeons practicing in the US, schedule corneal transplants for patients on an elective basis, similar to a cataract surgery. Additionally, modern corneal storage media and air transportation allow corneas to be easily transported both nationwide and worldwide so those fears may be baseless. Despite this, even if the surgery is done on an elective basis, will cornea surgeons accept last minute cancelations and changes to their operative schedule if flights are delayed and tissue does not arrive in time? While eye banks traditionally benefit the local community where the tissue was procured in first, it is not clear that this is the most efficient distribution of resources, or is it clear that the local cornea surgeons and patients will be adversely impacted by the export of tissues to other parts of the country.

It is not a foreign concept to a capitalistic society that when there is more competition, the consumer generally benefits. In this case, the consumers are both the patient and the cornea surgeon. SightLife's supporters argue that, due to a national collaboration, there will be a larger number of high-quality donors than there otherwise would be in an independent, community-based eye banking model. Moreover, it is not secret that local eye banks have already been forced to undergo consolidation. Today, eye banking is both more complex and more expensive than ever. Because of this, smaller eye banks have struggled to keep up and have been forced to either consolidate or fail. In some cases, SightLife offers to partner with local eye banks, if they agree to operate within the parameters of SightLife's contract. Generally, eye banks choosing to join SightLife are required to forfeit their surgeon partnerships to CorneaGen in exchange for equity ownership in the company. SightLife typically allows them to continue operating in the recovery capacity. Nevertheless, SightLife is not unique in its collaboration with local eye banks. Tissue sharing arrangements between local eye banks across the nation, such as Vision-Share and United-Sight, have been operational for many years. This allows banks who have an excess or shortage of tissue to share them, both domestically and internationally. ${ }^{8}$ While competition is largely beneficial, perhaps the presence of SightLife and their overture of salesmanship in markets 
that have a well-established eye bank may alienate cornea surgeons or regional eye banks; is this truly helpful for the industry of eye banking?

OPOs have been around since 1984, but they are relatively new to eye donation. OPOs are deemed the "gatekeepers" of the organ donation process and are federally backed agencies. There are currently 58 OPOs in the US, and they, according to their website, serve two major functions: ${ }^{9}$ first, to increase the number of registered donors and, second, to coordinate the donation process, which includes discussing donation with family members, finding a matching recipient, and very notably, arranging for the recovery and transport of donated organs. It is important to note that OPOs must be certified by the Centers for Medicare and Medicaid Services (CMS) and abide by CMS regulations. Due to this, OPOs carry a level of legitimacy that is difficult to match. Their emergence into eye tissue donation appears to be a result of contracting with SightLife as a way for them to expand their market share in eye tissue procurement, transportation, and processing. For example, an OPO in Wisconsin that is not involved in recovery, storage, processing, or distribution, is currently recruiting hospitals to sign eye donor referral/ recovery contracts with the OPO, subsequently rendering the responsibility and services to SightLife for their extensive expertise. SightLife employees then perform the actual recovery, shipping the corneas out of Wisconsin to one of the CorneaGen's distribution centers. Using OPOs to enlist the support of their region's hospital administrators is obviously more effective than asking these administrators to abandon their partnerships with their local eye bank.

Conversely, supporters of SightLife's model point to a roughly stable number of corneal transplants in the US at 50,000 per year as a reason traditional eye banks are not sustainable. This is because excess corneal tissue procured in the US is exported out of the country for transplantation or research purposes. A large hurdle every eye bank faces is that oftentimes tissue distribution outside of the country or tissue used for teaching and research generates fees below the cost of acquisition, processing, and distribution. Traditional eye banks operate as a non-profit, fee-for-service organization at modest margins of profit, enough to cover equipment costs, maintenance, and other operating expenses. However, since there are only a certain number of corneal transplants that occur in the US each year, there are a limited number of opportunities for maximum reimbursement. SightLife supporters argue that with their larger infrastructure in place, their ability to use economies of scale will allow more opportunities to export the tissue to areas of the world where it is most needed while operating at a smaller deficit relative to local operations.

Perhaps the greatest benefit that SightLife can provide to the world is the innovative research being done by its subsidiary, CorneaGen. From information on their website, Professor Shigeru Kinoshita is developing Injectable Endothelial Cell Therapy. The company is also looking into additives to the solutions in which corneas are immersed to remove organisms that could cause disease. ${ }^{10}$ It is not unheard of in the scientific community for non-profit companies to invest in for-profit entities in order to further their mission. This is known as venture philanthropy. Notably, the nonprofit Cystic Fibrosis Foundation had invested in the forprofit Vertex Pharmaceuticals since the late 1990s. Vertex eventually made a breakthrough discovery in 2012 leading to a $\$ 3.3$ billion windfall profit which ultimately furthered the mission of the Foundation, aiming at finding a cure for its namesake disease. ${ }^{11}$ Perhaps the SightLife Board of Directors founded SightLife Surgical (now CorneaGen) with similar dreams and aspirations to cure blindness but is this a fair comparison? Can we compare a monetary donation to generously gifted corneal tissue?

As discussed, CorneaGen is a mission-driven, for-profit business entity separate from SightLife with the goal to end corneal blindness by the year 2040. Some of their investments into research include improved corneal preservation media, endothelial cell transplantation, and the eventual replacement of human donor corneal allografts by artificial bioengineered corneas. It comes as no surprise that research carries a high price tag, one that most eye banks cannot compete with. Nevertheless, several of the Lions Eye Bank locations, for example, support research programs in the area indirectly by supplying specimens to study at cost. Discoveries in the aforementioned areas would certainly be enormous for patients and cornea surgeons, but would adversely affect eye banks, both community-based and SightLife, effectively making the need for human tissue obsolete.

Possibly, the most controversial aspect of the debate is the non-profit status of SightLife and how intimately it is related to the for-profit company CorneaGen. The companies have identical mission statements, though they have separate boards of directors. Nonetheless, the companies share 13 members on the board of medical directors and advisors leading to some degree of ambiguity in the minds of cornea surgeons. The non-profit organization, SightLife, recovers the tissue, but the for-profit organization, CorneaGen, processes, evaluates, and distributes the tissues to the cornea surgeons (Figure 1). ${ }^{12}$ It appears SightLife has very little to do with the gift once it has 


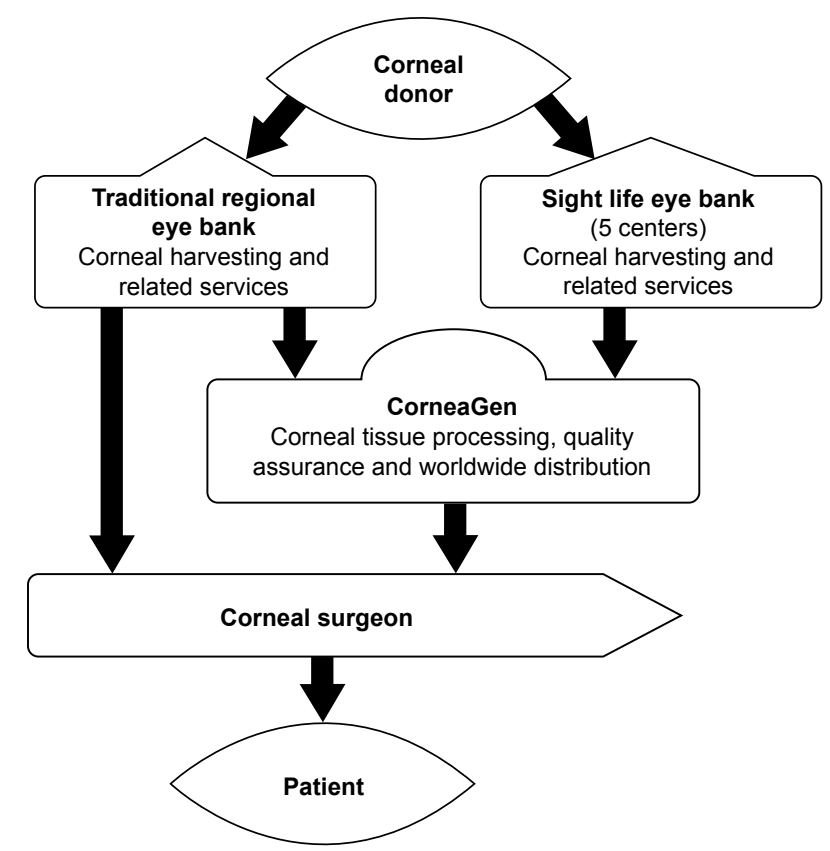

Figure I Traditional Eye Bank and Sight Life/CorneaGen Services for Corneal Transplants.

been recovered, meaning that OPOs are providing a for-profit firm with the tissue. Defenders of SightLife and CorneaGen respond to this criticism by noting that CorneaGen operates under National Organ Transplantation Act, which states that it is illegal to buy or sell organs and tissues, but it is legal to obtain reasonable payment associated with the removal, transportation, processing, preservation, quality control, and storage of corneas and eye tissue. Similarly, local eye banks routinely obtain payment related to these actions. ${ }^{13}$ Prior to the launch of SightLife Surgical in October 2016, several due diligence reviews were conducted with independent legal firms scrutinizing World Health Organization, US Food and Drug Administration, and Eye Bank Association of America regulations prior to formalizing the company. The reviews found that the business strategies of CorneaGen do not conflict with any of these regulations or principles. Regardless of the legality of the process, ethical questions remain.

Some argue that the for-profit connection fundamentally alters the relationship between the physician, eye bank, and donor by rendering the gift of the tissue as a commodity. ${ }^{14}$ The ethical discussion this leads to is crucial to the future of eye banks. This issue is especially concerning when considering that CorneaGen may eventually be a publicly traded company and subsequently will have a responsibility to their shareholders to maximize revenue. If reimbursement is highest when the tissue is used for transplants in the US, how can it be guaranteed that they will continue to devote tissue to research and export it outside of the country? This is not to say that SightLife is abusing its status as a non-profit, however. Rather than focusing on self-preservation, SightLife has partnered with multiple global nongovernment organizations, with the mindset to eliminate corneal blindness. For example, since 2009 they have restored sight to over 57,000 people in developing countries through cornea transplantation and provided training to over 200 cornea surgeons worldwide. ${ }^{15}$ This may be something that local eye banks do not have the resources to accomplish on the same scale.

While this is a complex issue that cornea surgeons are faced with, it is crucial to be informed about how the shifting paradigm may have long-reaching effects on the tissue supply, patients, potential donors, and the transplant procedure itself. Both sides make equally compelling arguments as to why their model should be the standard of care, and as such, the issue is worthy of more debate and scrutiny. We hope not to provide answers, but to present the issue in the context of a world where disruptive technology and ideas are celebrated, all while respecting the successful history of local, independently-run eye banks.

\section{Acknowledgments}

None of the authors have financial interest in any content mentioned in this article. This research has been supported by Research to Prevent Blindness (New York, NY, USA).

\section{Disclosure}

The authors report no conflicts of interest in this work.

\section{References}

1. Payne JW. New directions in eye banking. Available from: https://www. ncbi.nlm.nih.gov/pmc/articles/PMC1312164/pdf/taos00021-1008.pdf. Accessed July 4, 2018.

2. Gain P, Jullienne R, He Z, et al. Global survey of corneal transplantation and eye banking. JAMA Ophthalmol. 2016;134(2):167.

3. So you want to be a global nonprofit? Available from: http://media. johnwiley.com.au/product_data/excerpt/24/11184522/1118452224-109. pdf. Accessed July 9, 2018.

4. SightLife board member honored with first Diane Sabin Mission Impact Award created in her name; 2017. Available from: https://www.sightlife. org/Media/Default/Assets/AboutUs/ForMedia/SightLife\%20-\%20 Diane\%20Sabin\%20Mission\%20Impact\%20Award\%201-23-17.pdf. Accessed July 9, 2018.

5. EBAA. Eye banking statistical report. Eye Bank Assoc Am. 2017;(202): 1-99. Available from: www.restoresight.org. Accessed July 09, 2018.

6. Ruth N, Peralta V. 2015 Eye banking statistical report. Eye Bank Assoc $A m$. Washington DC. Available from: www.restoresight.org. Accessed July 9, 2018.

7. Verheijde JL, Rady MY, McGregor JL. The United States Revised Uniform Anatomical Gift Act (2006): new challenges to balancing patient rights and physician responsibilities. Philos Ethics Humanit Med. 2007;2(1): 19

8. About US - United sight eye bank group. Available from: http:// unitedsight.org/about-us/. Accessed July 9, 2018. 
9. Organ Procurement Organization (OPO) [homepage on the Internet]. List | organdonor.gov. U.S. Government Information on Organ Donation and Transplantation. Available from: https:/www.organdonor gov/awareness/organizations/local-opo.html. Accessed July 9, 2018.

10. CorneaGen [homepage on the Internet]. Available from: https:// corneagen.com/Services-Products/Medical-Advancement.aspx. Accessed December 10, 2018.

11. Tozzi J. This medical charity made $\$ 3.3$ billion from a single pill - bloomberg. Available from: https:/www.bloomberg.com/news/ features/2015-07-07/this-medical-charity-made-3-3-billion-from-asingle-pill. Published 2015. Accessed July 9, 2018.

12. Cornea Gen [homepage on the Internet]. Available from: https:// corneagen.com/Services-Products/Tissue-Services.aspx. Accessed July 9, 2018
13. Hatch $\mathrm{O}$ [homepage on the Internet]. National Organ Transplant Act (1984; 98th Congress S. 2048) - GovTrack. Us. Washington DC: United States Congress; 1983. Available from: https://www.govtrack. us/congress/bills/98/s2048. Accessed July 9, 2018.

14. Mannis MJ, Sugar J. Is this the future of eye banking? Cornea. 2018; 37(7):811-812.

15. SightLife - Resources - global partners [homepage on the Internet]. Available from: https://www.sightlife.org/Resources/Global-Partners. Accessed July 9, 2018.
Clinical Ophthalmology

\section{Publish your work in this journal}

Clinical Ophthalmology is an international, peer-reviewed journa covering all subspecialties within ophthalmology. Key topics include: Optometry; Visual science; Pharmacology and drug therapy in eye diseases; Basic Sciences; Primary and Secondary eye care; Patien Safety and Quality of Care Improvements. This journal is indexed on

Submit your manuscript here: http://www.dovepress.com/clinical-ophthalmology-journal

\section{Dovepress}

PubMed Central and CAS, and is the official journal of The Society of Clinical Ophthalmology (SCO). The manuscript management system is completely online and includes a very quick and fair peer-review system, which is all easy to use. Visit http://www.dovepress.com/ testimonials.php to read real quotes from published authors. 